\title{
Method Development and Validation of Visible Spectroscopic Method for the Estimation of Paroxetine Hydrochloride in Pure and Tablet Dosage Form
}

\author{
L. SIVA SHANKER REDDY ${ }^{2}$, T. RAJKUMAR ${ }^{2}$ and D. JENNY SUSHMITHA EVANGILINE ${ }^{1}$
}

${ }^{1}$ Department of Pharmaceutical Analysis \& Quality Assurance, ${ }^{2}$ Department of Pharmaceutical Chemistry, Creative Educational Society's College of Pharmacy, Chinnatekur, Kurnool -518218, Andhra Pradesh, India

shiva_s_rl@yahoo.co.in

Received 22 April 2017 / Accepted 21 May 2017

\begin{abstract}
The present research work discusses the development of visible spectroscopic method for the estimation of paroxetine hydrochloride. The optimum conditions for the analysis of the drug were established. The maximum wavelength $\left(\lambda_{\max }\right)$ was found to be $538 \mathrm{~nm}$. The validation was performed as per ICH guidelines for linearity, accuracy, precision, LOD and LOQ. The method shows high sensitivity with linearity in the range of $200-600 \mu \mathrm{g} / \mathrm{mL}$ and shows a linear relationship between the absorbance and concentration with coefficient of correlation 0.999 . The regression of curve was $\mathrm{Y}=0.001 \mathrm{x}+0.007$. The precision of method was found to be good. The percentage recovery was found to be $105.02 \pm 0.0832$. The optimized method showed good reproducibility and recovery with RSD $<2 \%$. The proposed method will be suitable for analysis of paroxetine hydrochloride in bulk as well as pharmaceutical formulations in quality control purpose. It is thus concluded that the proposed method is new, simple, cost effective, safe, accurate, precise and environmental friendly.
\end{abstract}

Keywords: Paroxetine hydrochloride, Visible spectroscopic method, Sensitive, Validation, ICH guidelines

\section{Introduction}

Paroxetine; (3S, 4R)-3-[(1,3-benzodioxol-5-vloxy)methyl]-4-(4-flurophenyl)piperidine (PRX, Figure 1) is a new generation antidepressant drug. It exerts its antidepressant effect through a selective inhibition for the reuptake of the neurotransmitter serotonin by the presynaptic receptors. PRX is comparable to the tricyclic antidepressants in their clinical efficacy, however, PRX is safer and has greater acceptance by the patients ${ }^{1}$. It is also prescribed in the treatment of related disorders, such as obsessive-compulsive disorder, panic fits, social phobia and post traumatic stress ${ }^{2}$. PRX is devoid of sedative effect and remarkably safe in overdose. PRX takes 5.2 hours to reach the peak, with extended half-life ( 21 hours) that allowed the introduction of formulations for once-daily dosing ${ }^{3}$. These combined qualities 
made PRX the most widely prescribed antidepressants ${ }^{4}$. The methods reported for quantitative determination of PRX in tablets and/or biological fluids include voltammeter ${ }^{5,6}$, densitometry ${ }^{7,8}$, high-performance liquid chromatography ${ }^{9-14}$, gas chromatography ${ }^{15-17}$ and capillary electrophoresis ${ }^{18}$. These methods offered the required sensitivity and selectivity for the analysis of PRX in biological fluids; however, their sophisticated instrumentation and high analysis cost limited their routine use in quality control laboratories for analysis of PRX in its pharmaceutical tablets.<smiles>Fc1ccc([C@H]2CCNC[C@H]2COc2ccc3c(c2)OCO3)cc1</smiles>

Figure 1. Structure of paroxetine hydrochloride

\section{Experimental}

A Lab India model 3000+ double beam UV-Visible spectrophotometer with two matched cuvette cells of one $\mathrm{cm}$ light path were used for the measurement of absorbance.

\section{Preparation of standard stock solution}

Accurately weighed $100 \mathrm{mg}$ of paroxetine hydrochloride was transferred into 100 volumetric, methanol was added to dissolve and volume was made up to $100 \mathrm{~mL}$ with water to get a concentration of $1000 \mu \mathrm{g} / \mathrm{mL}$.

\section{Determination of $\lambda_{\max }$}

From the stock solutions, $6 \mathrm{~mL}$ of paroxetine hydrochloride was transferred to $10 \mathrm{~mL}$ volumetric flask, $1 \mathrm{~mL}$ of sulphanilic acid - Sodium nitrite solution was added and the volume was adjusted to the mark with distilled water to obtain strength of $600 \mu \mathrm{g} / \mathrm{mL}$. The solution was scanned in the UV- Visible range 200-800 $\mathrm{nm}$ (Figure 2).

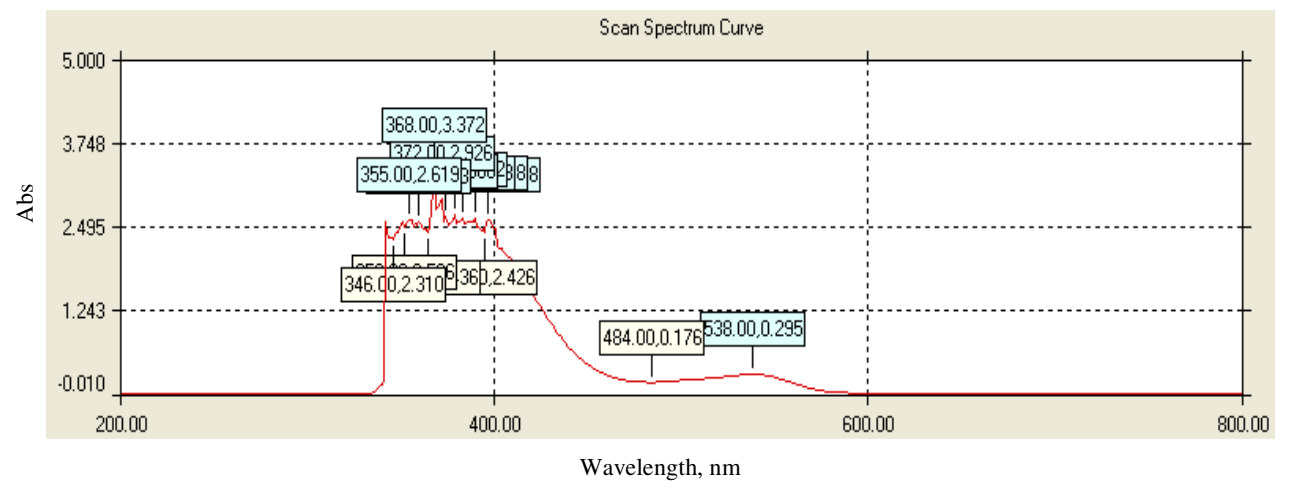

Figure 2. Spectrum of paroxetine hydrochloride

\section{Preparation of sulphanilic acid-sodium nitrite reagent}

$0.1 \mathrm{~g}$ of Sulfanilic acid is added with $4 \mathrm{~mL}$ of $\mathrm{HCl}$ and water in a beaker. $0.1 \mathrm{~g}$ of sodium nitriteis added with $4 \mathrm{~mL}$ of water. These two solutions are mixed and maintained at $0-5{ }^{\circ} \mathrm{C}$. 


\section{Construction of calibration curve}

Calibration curve was plotted against concentration and absorbance, regression equation was computed. The results are tabulated in the Table 1 and Figure 3.

Table 1. Calibration of proposed method

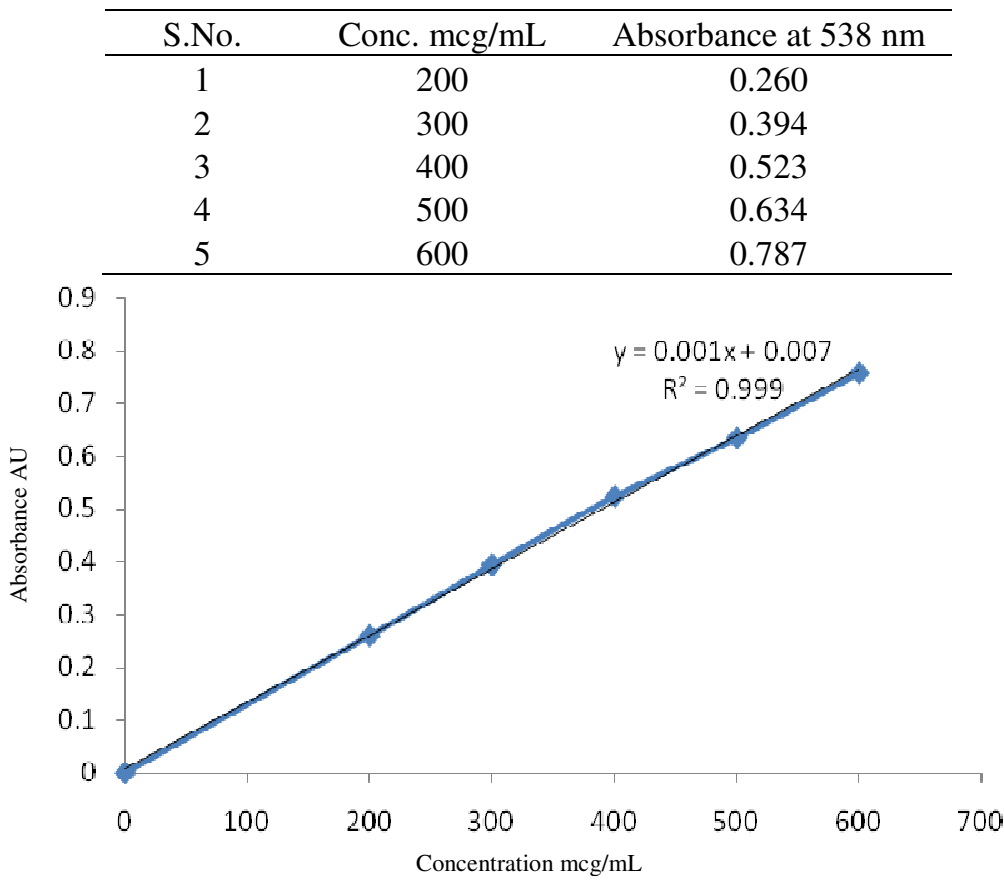

Figure 3. Calibration curve of paroxetine hydrochloride at $538 \mathrm{~nm}$

\section{Preparation of sample solution}

10 Tablets were weighed, average weight was determined. Tablets were powdered and the quantity of powder equivalent to $200 \mathrm{mg}$ of paroxetine $\mathrm{HCl}, 50 \mathrm{~mL}$ of methanol was added to dissolve. Excipients were filtered and to this solution $2 \mathrm{~mL}$ of sulfanilic acid reagent sodium nitrite solution was added and the absorbance was measured.

\section{Method validation}

The proposed method was validated as per the ICH Q2 (R1) guidelines for linearity, accuracy, precision, LOD and LOQ.

\section{Accuracy}

Accuracy was carried out at $80 \%, 100 \%$ and $120 \%$ of target concentration. From the amount found, percentage recovery was calculated.

\section{Precision}

Precision of the method was studied by carrying out intraday, interday analysis and expressed as percentage relative standard deviation. For this purpose 200 (LQC), 400 (MQC) and $600 \mu \mathrm{g} / \mathrm{mL}$ (HQC) solutions were prepared and the absorbances of the solutions were measured for six times within the same day and in different days at $538 \mathrm{~nm}$ against blank. 


\section{Limit of detection (LOD) and Limit of quantification (LOQ)}

LOD and LOQ of the drug were calculated using the following equations according to International Conference on Harmonization (ICH) guidelines

$$
\mathrm{LOD}=3.3 \times \sigma / \mathrm{S} \text { and } \mathrm{LOQ}=10 \times \sigma / \mathrm{S}
$$

Where $\sigma=$ the standard deviation of the response; $\mathrm{S}=$ the slope of the regression equation.

\section{Results and Discussion}

The proposed method for determination of paroxetine hydrochloride in marketed formulation (tablet) showed Sandell's sensitivity of $0.7692 \mu \mathrm{g} / \mathrm{cm}^{2} / 0.001$ absorbance units. Linear regression of absorbance on concentration gave the equation $\mathrm{y}=0.001 \mathrm{x}+0.007$ with $\mathrm{a}$ regression co-efficient $\left(\mathrm{r}^{2}\right)$ of 0.999 and the linearity range was $200-600 \mu \mathrm{g} / \mathrm{mL}$. The higher percentage recovery value indicates that there is no interference of the excipients present in the formulation (Table 2). Assay of paroxetine hydrochloride formulation was found to be $92 \%$ 0.33 is shown in Table 3. The accuracy studies and the percentage recovery was found to be $103.25 \pm 0.091$ to $106.64 \pm 0.090$ (Table 4). Precision and accuracy were studied and \% RSD value for all key parameters was less than $2 \%$ (Table 5). Thus the method is useful for the determination of paroxetine hydrochloride in bulk and pharmaceutical formulations.

Table 2. Optimum conditions, Optical characteristics and statistical data of the regression equation in visible spectroscopic method

\begin{tabular}{ll}
\hline \multicolumn{1}{c}{ Parameter } & Colorimetric method \\
\hline$\lambda_{\text {max }} \mathrm{nm}$ & 538 \\
Beer's law limits, mcg/mL & $200-600$ \\
Sandell's sensitivity & 0.7692 \\
(mcg / cm $^{2}-0.001$ absorbance units) & \\
Regression equation ( $\mathrm{Y}^{*}$ ) & $\mathrm{y}=0.001 \mathrm{x}+0.007$ \\
Slope (b) & 0.001 \\
Intercept (a) & 0.007 \\
Correlation coefficient $\left(\mathrm{r}^{2}\right)$ & 0.999 \\
$\%$ RSD & $<2 \%$ \\
Limit of detection, $\mathrm{mcg} / \mathrm{mL}$ & 85 \\
Limit of quantitation, $\mathrm{mcg} / \mathrm{mL}$ & 268 \\
\hline
\end{tabular}

${ }^{*} y=b x+a$ where $x$ is the concentration of paroxetine hydrochloride in $m c g / m L$ and $Y$ is the absorbance at the respective max. ${ }^{* *}$ Average of six determinations

Table 3. Assay of paroxetine hydrochloride formulation

\begin{tabular}{cccccc}
\hline S.No & Formulation & $\begin{array}{c}\text { Label claim } \\
(\mathrm{mg} / \mathrm{tab})\end{array}$ & $\begin{array}{c}\text { Amount found, mg } \\
(\mathrm{n}=3) \text { Mean } \pm \mathrm{SD}\end{array}$ & Assay & \%RSD \\
\hline 1 & Paxidep CR & $25 \mathrm{mg}$ & $23 \pm 0.054$ & $92 \%$ & 0.33 \\
\hline
\end{tabular}

Table 4. Determination of accuracy results for paroxetine hydrochloride

\begin{tabular}{cccccc}
\hline Name & $\begin{array}{c}\text { Amount of } \\
\text { sample } \\
\mathrm{mcg} / \mathrm{mL}\end{array}$ & $\begin{array}{c}\text { \% of } \\
\text { Spiked } \\
\text { sample }\end{array}$ & $\begin{array}{c}\text { Amount of } \\
\text { drug added } \\
\mathrm{mcg} / \mathrm{mL}\end{array}$ & $\begin{array}{c}\text { Amount } \\
\text { Recovered }\end{array}$ & $\begin{array}{c}\% \text { Recovery } \\
\pm \text { SD }\end{array}$ \\
\hline Paxidep CR & 1.6 & 80 & 2 & 383.93 & $106.64 \pm 0.090$ \\
Paxidep CR & 2 & 100 & 2 & 413.00 & $103.25 \pm 0.091$ \\
Paxidep CR & 2.4 & 120 & 2 & 462.71 & $105.16 \pm 0.1$ \\
\hline
\end{tabular}


Table 5. Determination of precision results for paroxetine hydrochloride

\begin{tabular}{ccccc}
\hline $\begin{array}{c}\text { Conc. } \\
\mathrm{mcg} / \mathrm{mL}\end{array}$ & $\begin{array}{c}\text { Inter-day } \\
\text { Absorbance } \\
\text { Mean } \pm \text { SD }\end{array}$ & \% RSD & $\begin{array}{c}\text { Intra-day } \\
\text { Absorbance } \\
\text { Mean } \pm \text { SD }^{*}\end{array}$ & \% RSD \\
\hline LQC, $200 \mathrm{mcg} / \mathrm{mL}$ & $0.263 \pm 0.0025$ & 0.951 & $0.266 \pm 0.0026$ & 0.977 \\
MQC, $400 \mathrm{mcg} / \mathrm{mL}$ & $0.525 \pm 0.002$ & 0.381 & $0.515 \pm 0.0032$ & 0.621 \\
HQC, $600 \mathrm{mcg} / \mathrm{mL}$ & $0.784 \pm 0.0025$ & 0.318 & $0.785 \pm 0.004$ & 0.510 \\
\hline
\end{tabular}

\section{Conclusion}

*Average of six determinations

A simple, sensitive, accurate and precise visible spectroscopic method has been developed for quantitative determination of paroxetine hydrochloride in bulk and pharmaceutical dosage form (tablet). The solution was scanned between 400 to $800 \mathrm{~nm}$ and $538 \mathrm{~nm}$ was selected as maximum wavelength for absorption. Beer's law was obeyed in the concentration range of $200-600 \mu \mathrm{g} / \mathrm{mL}$. \% Recovery was found to be $103.25 \%-106.64 \%$ and the method was successfully applied to the pharmaceutical dosage form containing the paroxetine hydrochloride drug without any interference of the excipients. The method was fast and economical and it was also selective and sensitive for the desirable range. Results of the analysis were validated as per ICH guidelines and by recovery studies.

\section{References}

1. Potter W Z and Hollister L E, Basic and Clinical Pharmacology. $9^{\text {th }}$ Ed., New York: c Graw Hill; 2004.

2. Sweetman S C, Martindale: The Complete Drug Reference. $34^{\text {th }}$ Ed., London, (UK): Pharmaceutical Press, 2005.

3. Tucker P, Zaninelli R, Yehuda R, Ruggiero L, Dillingham K and Pitts C D, J Clin Psychiatry, 2001, 62(11), 860-868.

4. Iversen L, Glennon R A and Abraham D J, Burger's Medicinal Chemistry and Drug Discovery. New York: John Wiley and Sons; 2003.

5. Nouws H P A, Delerue C, Barros A A and Rodrigues J A, J Pharma Biomed Anal., 2006, 42(3), 341-346; DOI:10.1016/j.jpba.2006.04.015

6. $\quad$ Erk N and Biryol J, Pharmazie, 2003, 58(10), 699-704.

7. Robert S, Genowefa M and Marcin K, J Planar Chromatography, 2003, 16(1), 19-22; DOI:10.1556/JPC.16.2003.1.4

8. Venkatachalam A and Chatterjee V S, Analytica Chimica Acta, 2007, 598(2), 312317; DOI:10.1016/j.aca.2007.07.014

9. Zainaghi I A, Lanchote V L and Queiroz R H C, Pharma Res., 2003, 48(2), 217-221; DOI:10.1016/S1043-6618(03)00098-7

10. Zhu Z and Neirinck L, J Chromatogr B, 2002, 780(2), 295-300; DOI:10.1016/S15700232(02)00537-8

11. Massaroti P, Cassiano N M and Duarte L F, J Pharmacy Pharmaceutical Sciences, 2005, 8(2), 340-347.

12. Jhee O H, Seo H K, Lee M H, et al.,Arzneimittel Forschung, 2007, 57(7), 455-461; DOI:10.1055/s-0031-1296631

13. British Pharmacopoeia 2003, the Stationary Office, London, UK, 2003.

14. United States Pharmacopeial Convention, the United States Pharmacopeia 31, the National Formulary 26, United State Pharmacopeia, Rockville, Md, USA, 2008. 
15. Eap C B, Bouchoux G, Amey M, Cochard N, Savary L and Baumann P, J Chromatogr Sci., 1998, 36(7), 365-371; DOI:10.1093/chromsci/36.7.365

16. Hans J L, Werner W and Günter F, J Chromatography B, 2002, 779(2), 353-357; DOI:10.1016/S1570-0232(02)00378-1

17. Chien L, Emily S G, Sidney H K, Alan N, Ronald T C and Glen B B, J Chromatogr $B$, 2000, 749(2), 275-279; DOI:10.1016/S0378-4347(00)00389-3

18. Labat L, Deveaux M, Dallet P and Dubost J P, J Chromatography, 2002, 773(1), 17-23; DOI:10.1016/S1570-0232(01)00623-7 